\title{
DELAYED REWARD DISCOUNTING \\ IN ALCOHOL ABUSE
}

\author{
Rudy E. Vuchinich \\ Cathy A. Simpson
}

Working Paper 6410 


\title{
NBER WORKING PAPER SERIES
}

\section{DELAYED REWARD DISCOUNTING IN ALCOHOL ABUSE}

\author{
Rudy E. Vuchinich \\ Cathy A. Simpson
}

Working Paper 6410

http://www.nber.org/papers/w6410

\section{NATIONAL BUREAU OF ECONOMIC RESEARCH \\ 1050 Massachusetts Avenue \\ Cambridge, MA 02138 \\ February 1998}

This paper has been prepared for the National Bureau of Economic Research conference, The Economic Analysis of Substance Use and Abuse: An Integration of Econometric and Behavioral Economic Research, March 27 and 28, 1997, Cambridge, Massachusetts. Any opinions expressed are those of the authors and not those of the National Bureau of Economic Research.

(C) 1998 by Rudy E. Vuchinich and Cathy A. Simpson. All rights reserved. Short sections of text, not to exceed two paragraphs, may be quoted without explicit permission provided that full credit, including $(\odot)$ notice, is given to the source. 
Delayed Reward Discounting in Alcohol Abuse

Rudy E. Vuchinich and Cathy A. Simpson

NBER Working Paper No. 6410

February 1998

\section{$\underline{\text { ABSTRACT }}$}

This paper summarizes studies that investigated the relation between temporal discounting and alcohol consumption. The first study compared heavy and light social drinkers, and the second study compared problem and light drinkers, on the degree to which they discounted the value of (hypothetical) amounts of money available after a series of delays. Heavy social drinkers and problem drinkers both showed higher rates of temporal discounting than light drinkers, and this difference was stronger in the second study. Both of these laboratory studies found that a hyperbolic function more accurately described temporal discounting than an exponential function. A third study evaluated predictors of relapse and continued resolution in problem drinkers who attempted to quit problem drinking without treatment. The outcome groups were distinguished by the preresolution proportions of discretionary expenditures they allocated to alcohol and savings. The data from these studies are consistent with extending behavioral theories of intertemporal choice to characterizing the determinants of alcohol consumption; they also are consistent with more general behavioral economic and economic theories of addiction that predict a positive relation between temporal discounting and addiction.

Rudy E. Vuchinich

Department of Psychology

Auburn University

Auburn, AL 36849

vuchire@mail.auburn.edu
Cathy A. Simpson

Department of Psychology

Auburn University

Auburn, AL 36849 
Delayed Reward Discounting in Alcohol Abuse

Rudy E. Vuchinich and Cathy A. Simpson

Auburn University

\section{INTERTEMPORAL CHOICE, DISCOUNTING, AND DRINKING}

Behavioral theory and research frame issues concerning impulsiveness and self-control within the context of intertemporal choice between smaller sooner rewards (the impulsive choice) and larger later rewards (the self-controlled choice) (e.g., Ainslie, 1975, 1992; Logue, 1988; Rachlin, 1974, Rachlin \& Green, 1972). This behavioral conception of intertemporal choice has been extended to studying alcohol use and abuse (e.g., Vuchinich, 1997; Vuchinich \& Tucker, 1988), with alcohol consumption and nondrinking activities that are more valuable in the long run (e.g., satisfying intimate, family, or social relations, or academic or vocational success) being analogous, respectively, to the smaller sooner and larger later rewards used in the behavioral laboratory. Laboratory experiments with normal drinkers have found that preference for alcohol varies inversely with the amount and directly with the delay of nondrinking rewards (Chutuape, Mitchell, \& de Wit, 1994; Vuchinich \& Tucker, 1983; Vuchinich, Tucker, \& Rudd, 1987), and studies in the natural environment with persons with alcohol problems have found that their drinking varies directly with constraints on access to nondrinking rewards (Tucker, Vuchinich, \& Gladsjo, 1994; Tucker, Vuchinich, \& Pukish, 1995; Vuchinich \& Tucker, 1996).

The amounts and delays of the smaller sooner and larger later rewards are critical determinants of preference in intertemporal choice situations (Logue, 1988). Another critical influence on preference is the degree to which the value of delayed rewards are discounted during the times before they are available, with higher rates of temporal discounting producing a stronger preference for the smaller sooner reward (i.e, impulsiveness). Thus, an extension of this analysis 
to studying alcohol use and abuse implies that alcohol consumption would vary directly with the rate of delayed reward discounting. More generally, recent behavioral (Herrnstein \& Prelec, 1992), behavioral economic (Rachlin, 1997), and economic (Becker \& Murphy, 1988) theories of addiction all hold that higher rates of temporal discounting will increase the risk of addiction.

Two types of discount functions have dominated the relevant literatures: (1) A hyperbolic function, $v_{p}=V /(1+\underline{k D})$

which is common in the psychological literature (e.g., Ainslie, 1992; Mazur, 1987; Rachlin, Raineri, \& Cross, 1991), and (2) an exponential function, $\mathrm{V}_{\mathrm{p}}=\mathrm{Ve}^{-\mathrm{kD}}$

which is common in the economic literature (e.g., Becker \& Murphy, 1988; Kagel, Battalio, \& Green, 1995). In both equations, $v_{p}$ is the present (discounted) value of a delayed reward, $V$ is the undiscounted value of a delayed reward, $D$ is the delay from the present to receipt of a delayed reward, and $\underline{\mathrm{k}}$ is a constant that is proportional to the rate of discounting.

Hyperbolic and exponential discount functions imply quite different choice dynamics in intertemporal choice situations (e.g., Ainslie, 1975; 1992). According to the exponential function, each increment in delay produces a constant proportional decrement in reward value. Thus, when the smaller sooner and larger later rewards are discounted at the same rate, preference between them remains constant over time. In contrast, according to the hyperbolic function, an equal increment in delay will produce a larger decrement in reward value at short delays than at long delays. Thus, when the smaller sooner and larger later rewards are discounted at the same rate, preference between them will reverse as a function of time.

These relationships are shown schematically in Figure 1, which represents a highly simplified 
two-option (alcohol consumption and a nondrinking reward) intertemporal choice situation. Exponential discounting produces consistent preferences over time for either alcohol consumption or the nondrinking reward. Prior to the time that alcohol consumption is available, an individual with a higher exponential discount rate (top right panel of Figure 1) would consistently prefer drinking and would emit no behavior that produced access to the larger later nondrinking reward On the other hand, an individual with a lower exponential discount rate (bottom right panel of Figure 1) would show a consistent preference for not drinking and would emit nothing but behavior that produced access to the larger later nondrinking reward. In contrast, hyperbolic discounting produces inconsistent preferences over time for either alcohol consumption or the nondrinking reward. Prior to the time that alcohol consumption is available, an individual with a higher hyperbolic discount rate (top left panel of Figure 1) would shift earlier in time from preferring the nondrinking reward to preferring drinking, and would emit less behavior over a shorter duration that produced access to the larger later nondrinking reward. On the other hand, an individual with a lower hyperbolic discount rate (bottom left panel of Figure 1) would shift later in time from preferring the nondrinking reward to preferring drinking, and would emit more behavior over a longer duration that produced access to the larger later nondrinking reward. Either type of discount function would predict a positive relation between the rate of discounting and drinking, and it is possible that different groups distinguished on the basis of their drinking behavior would show different types of discount functions as well as different rates of discounting.

Insert Figure 1 about here 
Sarfati and White (1991) capitalized on the work of Rachlin, Logue, Gibbon, and Frankel (1986) and reported data that seemed to indicate that heavy social drinkers discounted delayed rewards at a higher rate than light social drinkers. Rachlin et al. (1986) attempted to synthesize behavioral research on intertemporal choice, which focuses on reward amount and delay to receipt, with cognitive research on risky choice (e.g., Kahneman \& Tversky, 1984), which focuses on reward amount and probability of receipt. The crux of Rachlin et al's. argument was that the effects on choice of probability of reward are reducible to the effects of delay of reward: Over a series of trials, a high probability outcome occurs more often than a low probability outcome; so, on average, high probability outcomes occur sooner after a given choice than low probability outcomes. Thus, high and low probabilities in risky choice correspond to short and long delays in intertemporal choice, respectively, and risk aversion and risk seeking in risky choice are special cases of impulsiveness and self-control in intertemporal choice, respectively.

In order to evaluate the correspondence between delay and probability, Rachlin et al. (1986) developed a repeated gambles procedure in which participants repeatedly chose between two roulette-type wheels, a "sure thing" that provided a smaller amount of (hypothetical) money at a high probability, and a "risky gamble" that provided a larger amount of (hypothetical) money at a lower probability. In this procedure, preference for the "sure thing" and "risky gamble" correspond to risk aversion and risk seeking, respectively. In their study, Rachlin et al. manipulated intertrial interval (ITI) across two groups of participants and found that the long ITI group chose the sure thing option more often than the short ITI group, which supported their synthesis of probability and delay and led them to attribute the greater risk aversion in the long ITI group to the effects of discounting of delayed rewards (i.e., impulsiveness).

Sarfati and White (1991) applied these concepts and methods to the study of individual 
differences in impulsiveness among social drinkers. They reasoned that, if alcohol consumption is an impulsive behavior in an intertemporal choice context, and if the repeated gambles procedure measures impulsiveness, as argued by Rachlin et al. (1986), then heavy drinkers should be more risk averse in the repeated gambles procedure than light drinkers. Their study compared the choices of heavy and light social drinkers in the repeated gambles procedure. Their results showed that heavy drinkers chose the sure thing option more often than light drinkers, which apparently indicated greater risk aversion among the heavy drinkers, and implied that heavy social drinkers discount delayed rewards at a higher rate than light social drinkers.

Sarfati and White's (1991) finding was somewhat surprising, however, given that Silberberg, Murray, Christensen, and Asano (1988) had reported four studies that strongly suggested that choice in the repeated gambles procedure is not affected by rates of temporal discounting. Moreover, the Sarfati and White (1991) study raised some questions about the relation between drinking and impulsiveness as defined in behavioral research on choice and impulsiveness as defined in research on personality characteristics. In the personality literature, impulsiveness is viewed as a multidimensional construct that is positively correlated with risk-taking (e.g., Gorenstein \& Newman, 1980; White, Moffit, Caspi, Bartusch, Needles, \& Stouthamer-Loeber, 1994). Also, positive relationships have been found between drinking and impulsiveness as measured by personality questionnaires (e.g., Sher \& Trull, 1994). Thus, Sarfati and White's (1991) results are not what would be expected from this literature. That is, if drinking and impulsiveness are positively related, and if impulsiveness (as measured by personality questionnaires) and risk-taking are positively related, then heavy drinkers should be more risk seeking (not more risk averse) than light drinkers in the repeated gambles procedure.

Because of these ambiguities, Vuchinich and Calamas (1997) attempted (1) to replicate Sarfati 
and White's (1991) finding that heavy drinkers are more risk averse than light drinkers in the repeated gambles procedure, and (2) to explore the empirical relations between drinking and impulsiveness as defined by personality questionnaires and impulsiveness as defined by choice in the repeated gambles procedure. The Vuchinich and Calamas study found no differences between heavy and light social drinkers in their choice in the repeated gambles procedure, thus failing to replicate Sarfati and White's main finding. Moreover, they found that risk seeking in the repeated gambles procedure was associated with more impulsiveness on the questionnaire measures. These results, along with Silberberg et al's. (1988) data, indicated that the repeated gambles procedure is not a useful method for studying delayed reward discounting and impulsiveness. Thus, the theoretical hypothesis of a positive relation between drinking and temporal discounting was not adequately evaluated by the Sarfati and White (1991) study.

\section{STUDIES WITH THE HYPOTHETICAL MONEY CHOICE TASK}

\section{Study 1: Comparing Temporal Discounting in Heavy and Light Social Drinkers}

The primary purpose of this study (Vuchinich \& Simpson, submitted) was to compare rates of delayed reward discounting in heavy and light social drinkers using a procedure that generates a quantitative estimate of the discount rate for individual participants and that can distinguish between hyperbolic and exponential discount functions. This procedure, which we will call the hypothetical money choice task, was developed by Rachlin et al. (1991) and subsequently used by Raineri and Rachlin, (1993), Green, Fry, and Myerson (1994), Green, Myerson, Lichtman, Rosen, and Fry (1996), and Myerson and Green (1995). The theoretical prediction was that heavy drinkers would have higher discount rates for delayed rewards than light drinkers. Moreover, given that several studies have found that the hyperbolic function describes temporal discounting more accurately than the exponential function (e.g., Rachlin et al., 1991; Myerson \& Green, 
1995), we also expected our data to favor the hyperbolic function.

\section{Method}

Students $(\underline{\mathrm{N}}=527)$ at Auburn University were screened with the Khavari Alcohol Test (KAT; Khavari \& Farber, 1978) and the Michigan Alcoholism Screening Test (MAST; Selzer, 1971) to assess their typical drinking and drinking problems, respectively. The KAT yields an annual absolute alcohol intake (AAAI) index that estimates total amount of alcohol consumption (in ounces of ethanol) during the previous year. Individuals with drinking problems, as assessed by the MAST, and those who abstained from alcohol were excluded from further participation. Students at the extremes of the remaining AAAI distribution were selected for the experimental phase of the study, resulting in a final sample of 24 heavy drinkers (12 males and 12 females) and 24 light drinkers (12 males and 12 females). The heavy and light drinkers were very different on the KAT AAAI index, with means of 404.57 and $25.98(\mathrm{p}<.001)$, respectively. Participants also completed a demographic questionnaire that asked about their personal and family incomes, and there were no between-group differences on these measures.

Participants came to the laboratory for individual sessions. They first completed the repeated gambles procedure, as in Sarfati and White (1991) and Vuchinich and Calamas (1997), and then the hypothetical money choice task (see Vuchinich \& Simpson, submitted, for details). This procedure yields multiple measures of the amount of immediately available (hypothetical) money that is subjectively equivalent in value to a larger amount of (hypothetical) money that is available after a set of delays. These multiple subjective equivalence points are then used to estimate the temporal discounting function. Participants repeatedly chose between a larger fixed-amount of money available after a delay and a smaller amount of money that was available immediately. There were four series of trials, two each in which the delayed fixed-amount rewards were $\$ 1,000$ 
and $\$ 10,000$. On each trial series, the large delayed money amount was constant across trials, and the smaller immediate money amount was changed on each trial. The smaller immediate money amounts consisted of 30 values ranging from $0.1 \%$ to $100 \%$ of the larger fixed amount. Each trial series was repeated 8 times at different delays of the larger fixed-amount reward: 1 week, 1 month, 6 months, 1 year, 3 years, 5 years, 10 years, and 25 years. Within each of the money amount conditions, in one trial series the immediate smaller money amounts were presented in ascending order and in one series they were presented in descending order.

We used Green et al's. (1994) procedure for determining the subjectively equivalent immediate amounts for each fixed amount at each delay. These equivalence points were calculated by averaging two values: (1) the value at which the participant switched preference from the immediate to the delayed reward when the immediate rewards were presented in descending order, and (2) the value at which the participant switched preference from the delayed to the immediate reward when the immediate rewards were presented in ascending order. These equivalence points for two individual participants, one with a relatively high discount rate and one with a relatively low discount rate, are shown in Figure 2.

Insert Figure 2 about here

\section{$\underline{\text { Results }}$}

Comparison of the drinker groups on their choices during the repeated gambles procedure revealed no difference, which replicated Vuchinich and Calamas's (1997) main finding. Our analyses of the hypothetical money choice task data first determined whether the hyperbolic (Equation 1) or exponential (Equation 2) discount function provided better fits to the data. Nonlinear regression analyses were used to estimate separate $\underline{\mathbf{k}}$ parameters based on Equations 1 
and 2 for both money amount conditions for each participant. The proportions of the variance in the data that were accounted for by the parameter estimates were entered into a $2 \times 2 \times 2 \times 2$ (Drinker Group X Sex X Money Amount X Equation) ANOVA, which revealed only a significant $(p<.001)$ main effect for type of equation. Equations 1 and 2 accounted for an average of $82 \%$ and $69 \%$ of the variance, respectively, which indicates better fits to the data with the hyperbolic discount function.

In order to evaluate group differences in the discounting parameter, the hyperbolic $\mathrm{k}$ parameters from the $\$ 1,000$ and $\$ 10,000$ condition were averaged for each participant and then entered into a 2 X 2 (Drinker Group X Sex) ANOVA, which yielded only a significant $(p=.04$, one tailed) main effect for Drinker Group. Heavy drinkers $(\underline{M}=.193, \underline{S D}=.450)$ had higher $\underline{k}$ values than light drinkers $(\underline{M}=.034, \underline{S D}=.030)$. Because the drinker group variances were heterogeneous, a nonparametric Mann-Whitney $\underline{U}$ test also was computed and yielded comparable results $(\mathrm{p}<.09$, one tailed). The median $\underline{\mathbf{k}}$ values for the heavy and light drinker groups were .039 and .026 , respectively. Figure 3 plots discount functions generated from Equation 1 using these median $\underline{\mathrm{k}}$ values. As can be seen in Figure 3, the discount function for the heavy drinkers is lower (higher $\underline{\mathrm{k}}$ values) than the corresponding function for the light drikers.

\section{Discussion}

The temporal discounting data clearly showed that the hyperbolic function is a more accurate description of delayed reward discounting than the exponential function for all participants, which is consistent with previous evidence from studies that directly compared the two functions (e.g., Rachlin et al., 1991; Myerson \& Green, 1995). Most important, heavy drinkers had higher rates 
of hyperbolic discounting than light drinkers, as predicted from the behavioral perspective on intertemporal choice, but the level of statistical significance was marginal.

\section{Study 2: Comparing Temporal Discounting in Problem Drinkers and Light Social Drinkers}

Alcohol consumption obviously is a multi-determined behavior (e.g., Abrams \& Niaura, 1987), and it would be unrealistic to expect one, or even several, variables to account for the bulk of inter-individual variability in levels of naturally occurring social drinking. This probably is especially true for drinking among college students, who are embedded in a social context in which heavy social drinking often is more normative than exceptional (e.g., Wechsler, Dowdall, Davenport, \& Castillo, 1995). Thus, the marginal significance of the discounting-drinking relation found in Study 1 may reflect the fact that many other variables are also converging to produce variability in social drinking. However, as drinking escalates beyond socially acceptable levels, which do not cause significant problems, to heavier, problem drinking, then we may expect a reduction in the number of critical variables. If that is the case, and if temporal discounting is among these more critical variables that are related to alcohol abuse, then a stronger discountingdrinking relation should be found if light social drinkers without alcohol problems are compared to heavy drinkers with alcohol problems. Conducting this comparison was the primary goal of Study 2 (Vuchinich \& Simpson, submitted).

\section{Method.}

Students $(\underline{N}=380)$ at Auburn University were screened using the KAT and the Young Adult Alcohol Problem Screening Test (YAPPST; Hurlbut \& Sher, 1992) to assess alcohol problems. The YAAPST was designed specifically for college-age samples and provides measures of both life-time and past-year frequency of alcohol problems in legal, occupational, health, family/marital, and social areas. Potential participants were excluded if they abstained from alcohol. Problem 
drinkers were defined as those potential participants at the upper extreme of the AAAI distribution who also reported at least five past-year alcohol problems on the YAAPST. Light drinkers were defined as those potential participants at the lower extreme of the AAAI distribution who also reported no more than one past-year alcohol problem on the YAAPST. The final study sample consisted of 31 participants, 16 problem drinkers ( 8 males and 8 females) and 15 light drinkers ( 7 males and 8 females). The problem and light drinkers were very different on the KAT AAAI index, with means of 1445.45 and $12.79(\mathrm{p}<.001)$, respectively, and on the number of alcohol problems reported on the YAAPST, with means of 8.93 and $0.00(p<.001)$, respectively. Participants also completed a demographic questionnaire that asked about their personal and family incomes, and there were no between-group differences on these measures.

Only the $\$ 1,000$ amount condition of the hypothetical money choice task was used during the laboratory sessions. At the end of the session, participants who were problem drinkers were told that the screening data indicated they may be experiencing alcohol problems. They were then given a list of substance abuse treatment agencies in the community and told they could contact one or more of them if they wished to seek assistance.

\section{Results}

Nonlinear regression analyses were used to estimate separate $\underline{\mathbf{k}}$ parameters based on Equations 1 and 2 for the $\$ 1,000$ money amount condition for each participant. The proportions of variance accounted for by each equation were entered into a 2 X 2 X 2 (Drinker Group X Sex X Equation) ANOVA, which revealed only a significant $(\mathrm{p}<.003)$ main effect for type of equation.

Fquations 1 and 2 accounted for an average of $80.05 \%$ and $70.12 \%$ of the variance, respectively, which indicates better fits to the data with the hyperbolic discount function.

The hyperbolic $\underline{\mathrm{k}}$ parameters from the $\$ 1,000$ condition were entered into a $2 \times 2$ (Drinker 
Group X Sex) ANOVA, which showed only a significant $(p<.025$, one tailed) main effect for drinker group. Problem drinkers $(\mathrm{M}=.104, \mathrm{SD}=.162)$ had higher $\mathrm{k}$ values than light drinkers $(\mathrm{M}=.018, \mathrm{SD}=.025)$. Because the drinker group variances again were heterogeneous, $\mathrm{a}$ nonparametric Mann-Whitney $\underline{U}$ test also was computed and yielded comparable results $(\mathrm{p}<.01$, one tailed). The median $\mathrm{k}$ values for the problem and light drinkers were .034 and .008 , respectively. Figure 4 plots discount functions generated from Equation 1 using these median $\underline{\mathrm{k}}$ values. As Figure 4 shows, the discount function for the problem drinkers is lower (higher $\underline{\mathrm{k}}$ values) than the corresponding function for the light drinkers, and the groups are more widely separated than in Study 1.

Insert Figure 4 about here

\section{Discussion}

As in Study 1, the hyperbolic function was a more accurate description of discounting than the exponential function, and the problem drinkers had higher $\underline{\mathrm{k}}$ values than the light drinkers. This discounting-drinking relation replicated and was stronger than the one found in Study 1, and involved fewer participants. The finding that heavy social drinkers and problem drinkers discount delayed rewards at a higher rate than light drinkers is similar to the results of Madden, Petry, Badger, and Bickel (1997), who found higher discount rates among opioid-dependent patients than among non-drug-using control participants.

There are several issues that are relevant to comparing the discount functions in Figures 3 and 4 from the two studies. First, the functions in Figure 3 from the first study were generated from averaging the $\mathrm{k}$ parameters from the $\$ 1,000$ and the $\$ 10,000$ money amount conditions, whereas the functions in Figure 4 from the second study were generated from the $\underline{k}$ parameters from the $\$ 1,000$ condition only. In Study 1, the $\$ 10,000 \underline{\mathbf{k}}$ values generally were higher than the $\$ 1,000 \underline{\mathbf{k}}$ 
values. Thus, the discount functions in Figure 3 are generally lower (higher $\underline{k}$ values) than those in Figure 4 because of the averaging of the two money amount conditions in Study 1.

Second, the context surrounding the hypothetical money choice task in the two studies was slightly different. Participants in the first study completed the repeated gambles procedure prior to the hypothetical money choice task, and participants in the second study did not. Also, Study 1 participants knew they would be making choices in both money amount conditions and Study 2 participants knew they would be making choices in only one money amount condition. Given that subtle contextual cues can have important effects on choice in such laboratory preparations (e.g., Kahneman \& Tversky, 1984; Silberberg et al., 1988), these procedural differences may have affected participants' choices in the two studies.

Third, the participant groups differed across the two studies in terms of both drinking behavior and the occurrence of alcohol problems. The problem drinkers in Study 2 drank more and had more problems than the heavy drinkers in Study 1, whereas the light drinkers in both studies were comparable in terms of drinking. Thus, comparisons across the two studies cannot determine if the larger discounting difference in Study 2 was due to the difference in drinking behavior, the difference in alcohol problems, or both. Disentangling these relations would seem to be a worthwhile empirical question for future research.

Finally, comparison of absolute values of data points across studies of this sort with relatively small samples is hazardous. This is especially true when the comparison is made on the basis of data values at certain percentile ranks, as apposed to mears and standard deviations, as representative of centplanffency and dispersion of the distributions. Thus, the most important comparison is between graups within a single study, as in any between-groups design. Different studies then can be compared on the basis of the strength of the ben-group differences found 
within each study, rather than on the basis of absolute data values. By this criterion, the difference between the problem and light drinker groups in Study 2 was considerably stronger than the difference between the heavy and light social drinker groups in Study 1.

It is significant that the drinker groups in these laboratory studies could be distinguished on the basis of the degree to which they discounted the value of money, a commodity which has no apparent connection with their alcohol consumption. This is consistent with the notion that behavior with respect to valuable commodities other than alcohol is at least as important as behavior with respect to alcohol in understanding the determinants of alcohol consumption, which is a major premise of a behavioral economic analysis of alcohol abuse (Vuchinich \& Tucker, 1988). Although the monetary discounting difference between the drinker groups presumably reflects general tendencies, in future research on the discounting-drinking relation it may be advantageous to explore the specificity of discounting the value of particular nondrinking activities. This would be the case because discount rates differ for different nondrinking rewards (Raineri \& Rachlin, 1993), and there likely are important between-individual differences and within-individual changes over time (e.g., Green et al., 1994) both in these particular discount rates and in the types of particular nondrinking activities that enter into intertemporal choice relations involving alcohol consumption (Vuchinich \& Tucker, 1988). Significant discountingdrinking relations were found in the present research for a single nondrinking reward (i.e., money), but stronger such relations may be found in future studies that measure discount rates for nondrinking rewards that are individually relevant for particular participants (Vuchinich \& Tucker, 1996).

The behavioral economic theoretical terms and methods employed in the current studies connect with a much broader theoretical and empirical literature on behavioral allocation, 
intertemporal choice, and economics (e.g., Kagel et al., 1995; Loewenstein \& Elster, 1992) that has been usefully applied to the study of substance use and abuse (e.g., Bickel, DeGrandpre, \& Higgins, 1993; DeGrandpre \& Bickel, 1996; Green \& Kagel, 1996; Vuchinich, 1995). Behavioral allocation, in general, and drug self-administration, in particular, by animals and humans in laboratory preparations and by humans in the natural environment can be described with the same theoretical terms, although their empirical interpretations differ across the different situations. Thus, the generality of relations found in one situation can be evaluated by applying the same theoretical terms, with appropriate empirical interpretations, to other situations. For example, it is intriguing that Paulos, Le, and Parker (1995) found that rats' preferences for a smaller sooner food reward over a larger later food reward were positively related to the amounts of alcohol they self-administered, which can be viewed as a discounting-drinking relation similar to that found in the present laboratory research with humans. The generality of the present findings to other participant populations in other situations with other abused substances remains to be evaluated.

\section{A STUDY OF PROBLEM DRINKERS IN THE NATURAL ENVIRONMENT}

\section{Study 3: Predicting Natural Resolutions of Alcohol Problems}

Most persons with alcohol problems never enter formal treatment (e.g., Room, 1989), yet many of those who remain untreated somehow resolve their drinking problem (Sobell, Cunningham, \& Sobell, 1996). One of us (REV) is currently involved in a longitudinal study (with Jalie A. Tucker, Principal Investigator) of untreated problem drinkers who attempted to quit problem drinking. The goal of this study is to identify pre- and postresolution variables that predict, promote, and hinder natural resolutions of alcohol problems. Of particular interest is whether the proportion of monetary resources allocated to alcohol consumption and other commodity classes during periods of problem drinking can serve as viable measures of the value 
of drinking and other activities. If so, then such measures derived from the time period prior to attempts to quit problem drinking may be useful in predicting outcomes and in understanding the dynamics of changes in drinking behavior. Some of the preliminary data from this study may be relevant to the discounting-drinking relation.

Method

Participants were solicited through media advertisements in major metropolitan areas of Alabama and Georgia; 58 individuals met DSM IV (American Psychiatric Association, 1994) diagnostic criteria for alcohol dependence, among other alcohol problem criteria, and had never participated in an alcohol treatment program or Alcoholics Anonymous. In addition, participants had quit problem drinking for no less than two months and no more than six months $(\underline{M}=3.85$ months) when inducted into the study.

Several measures were included that assessed the extent of drinking problems and levels of alcohol dependence. An expanded version of the Time Line Follow Back interview procedure (described in Vuchinich, Tucker, \& Harllee, 1988) was used to assess daily drinking, life events, and monetary variables over the 12 -month period prior to the resolution date, and then at $12-$ and 24-month follow-up intervals. The monetary variables are recorded so that amounts of income and expenditures are coded in specific categories (e.g., wage, salary, and pension for income; housing, transportation, food, entertainment, and savings for expenditures). The amount of money spent on alcohol also is recorded and can be expressed as a proportion of total income or expenditures or of the sums of groups of subcategories of either. The data presented here are from the 46 participants who have so far completed the 12-month follow-up assessment. $\underline{\text { Results }}$

Regarding the preresolution monetary variables, most participants had middle to upper 
incomes $(\underline{\mathrm{M}}=\$ 41,688$, range $=\$ 3,300$ to $\$ 250,000)$, and had organized their expenditures and lifestyles accordingly. For conceptual reasons and to reduce variance, we focused on discretionary expenditures, as opposed to total income or expenditures, as the pool of monetary resource. Discretionary expenditures included entertainment, tobacco, money given to another, alcohol, and savings, as contrasted with more obligatory expenditure categories such as housing, utilities, transportation, medical, food, and loan payments. Discretionary expenditures thus represents the allocation of unobligated income and seemed to be a suitable starting point for this generally economically advantaged sample.

Of the 46 participants, 16 had relapsed to problem drinking and 30 had maintained their resolutions one year after their quit dates. We conducted three discriminant function analyses (DFAs) that investigated predictors of the one-year outcome classification, one DFA each that included only pre- or postresolution variables and one DFA that included both.

The DFA for preresolution variables included alcohol dependence levels, income, heavy drinking days, legal problems, physical health problems, and the proportion of discretionary expenditures allocated to alcohol (Discretionary Ethanol Expenditures [DEE] index). These variables were included because of conceptual reasons, their demonstrated utility in past research with treated samples (e.g., Moos, Finney, \& Cronkite, 1990), or their ability to discriminate between the outcome groups. A significant discriminant function was found that included the DEE index $(\mathfrak{p}<.01)$, with relapsed participants having higher scores than resolved participants, and physical health problems $(\mathrm{p}<.05)$, with resolved participants having more problems than relapsed participants. This DFA achieved an overall correct (jackknifed) classification rate of $78 \%$.

The DFA for postresolution predictors included total positive and total negative life events, 
negative physical health events, and negative work events. This DFA also revealed a significant function that included negative work events $(\mathrm{p}<.01)$, with relapsed participants reporting mre events than resolved participants, and negative physical health events $(p<.05)$, with resolved participants reporting more events than relapsed participants. This DFA produced an overall correct classification rate of $74 \%$. The DFA that included both pre- and postresolution variables also produced a significant function that included the DEE index $(p<.01)$ and postresolution negative health events $(\mathrm{p}<.01)$, and correctly classified $78 \%$ of the participants.

As discussed earlier, the behavioral economic perspective views drinking as an impulsive behavior, as contrasted with behavior patterns that invest current resources in future activities of greater value. We therefore explored how the resolved and relapsed participants had allocated their discretionary expenditures to savings, as well as to drinking, during the preresolution year. The proportion of preresolution discretionary expenditures that were allocated to drinking and to savings by both participant groups were entered into a 2 X 2 (Outcome Group X Expenditure Type) ANOVA. A significant interaction effect $(p<.01)$ showed that the difference between the proportional alcohol and savings expenditures was greater for the relapsed participants $(\underline{\mathrm{Ms}}=$ $59 \%$ and $4 \%$, respectively) than for the resolved participants ( $\underline{\mathrm{Ms}}=34 \%$ and $17 \%$, respectively). Moreover, the outcome groups were similar in their expenditures in other categories, in their preresolution incomes and total expenditures, and in their preresolution drinking patterns.

\section{Discussion}

These results are preliminary and do not permit firm inferences. Nevertheless, the data are relevant in two particular ways to the present topic. First, the DEE index was the best predictor from the preresolution variables of the one-year outcomes. It is interesting that the DEE index was a better outcome predictor than more conventional variables, such as alcohol dependence 
levels, drinking practices, and income. This suggests that monetary resource allocation to alcohol consumption may be a useful way to represent its reward value in relation to nondrinking activities. Because discretionary expenditures are much less constrained than more obligatory expenditures, which often involve commitments over months or years, the former may be the arena in individuals' personal economies where an increasing preference for alcohol consumption are initially manifested and most clearly seen. Obligatory expenditure categories may initially be more durable in the face of escalating problem drinking, but eventually would be affected if problems become severe enough, as is often seen in treatment samples. The DEE index thus may be a good early indicator of the growing reward value of alcohol relative to nondrinking activities that is not highly correlated with drinking practices (the DEE correlated .22 with number of preresolution heavy drinking days and .46 with quantities of alcohol consumed per drinking day). Being able to measure the shift in resource allocation towards drinking and away from nondrinking activities would be useful in studying the dynamics of drinking problems in the natural environment.

Second, to the extent that savings is inversely related to temporal discounting, then the degree of temporal discounting during the preresolution year appears to have been a relevant variable in distinguishing the outcome groups. Participants who were resolved at the one-year follow-up allocated proportionally less money to alcohol and more to savings than those who were relapsed. This suggests that problem drinkers whose behavior is organized more around delayed outcomes (i.e., as reflected in savings), even during periods of problem drinking, are more likely to succeed in attempts to recover from their drinking problem.

\section{GENERAL DISCUSSION}

The main results of these studies supported predictions derived from extending behavioral 
conceptions of intertemporal choice to an analysis of the determinants of alcohol consumption. These results also are consistent with more general, formal theories (Becker \& Murphy, 1988; Herrnstein \& Prelec, 1992; Rachlin, 1997) that propose different choice dynamics to account for addiction but that all predict a positive relation between rates of temporal discounting and addiction. The current data are consistent with but cannot distinguish between these theories, except that Herrnstein and Prelec and Rachlin incorporate hyperbolic discount functions, whereas Becker and Murphy incorporate an exponential discount function. Although the use of hypothetical rewards in these laboratory studies demands caution in interpreting these data, the finding that a hyperbolic function provides a better description of temporal discounting than an exponential function appears to be quite general. As noted by Loewenstein (1996, p. 279), “The non-exponential discounting perspective has been bolstered by findings from hundreds of experiments showing that humans and other animals display hyperbolic discount functions of the type predicted to produce impulsive behavior . ..."

Because these studies were correlational, they cannot address the temporal priority of higher discount rates or heavy drinking. At this point, either preceding the other is equally plausible (Becker \& Mulligan, in press), but this issue would appear to be fairly easily disentangled in longitudinal studies. If such studies find that higher discount rates more often precede than follow heavy drinking, then measuring discount rates before the initiation of drinking potentially could aid in the identification of individuals at risk for developing heavy drinking and alcohol problems. Moreover, identifying the determinants of discounting and manipulating them could produce low discount rates and potentially help prevent the development of heavy drinking and alcohol problems and treat them once they occur. On the other hand, if higher discount rates are found more often to follow than to precede heavy drinking, it would remain possible for higher discount 
rates to be an important factor in the perpetuation of heavy drinking regardless of the initiating conditions. Although the data from Study 3 are preliminary, it appears that temporal discounting may have been a factor that distinguished successful and unsuccessful attempts to quit problem drinking without treatment.

These data also cannot address the conditions that generated the particular discount rates manifested by our participants. It is possible, for example, that the heavy and problem drinkers showed higher discount rates because their past and current environments had a sparsity of larger later nondrinking rewards relative to the light drinkers. If that is the case, however, the difference in larger later rewards must have been in areas other than socioeconomic, because the drinker groups in the laboratory studies were sampled from the same student population and did not differ on family or personal income, and the relapsed and resolved participants in Study 4 were not significantly different in income. On the other hand, it also is possible that the heavy/problem drinkers and light drinkers, and the relapsed and resolved drinkers, had similar reward structures in their environments but that some factor distinguished them as individuals or how they interacted with their environments that generated the different discount rates. There are, of course, other possibilities, and the point is that identifying the determinants of temporal discounting is an important topic for future research.

The relevant theoretical context within which to consider the rates of temporal discounting manifested by our participants in the laboratory studies can be given two different, general interpretations (cf., Rachlin, 1992, 1994). The discount rates can be regarded (1) as reflecting the operation of a cognitive mechanism, as one component of a representational system that includes other cognitive mechanisms, that partly causes certain choices at particular points in time (e.g., Kahneman \& Tversky, 1984) or (2) as a behavior-environment relation, as one component of a 
representational system that includes other behavioral and environmental variables, in a description of behavioral allocation patterns over time among available activities (e.g., Rachlin et al., 1986). According to the cognitive interpretation, each participant would have had experiences that instantiated (in principle) a particular discounting mechanism among the other cognitive mechanisms in their representational system. When faced with the procedures used in these studies, the participants' discounting mechanism would have mediated between the particular stimuli and their particular responses, thus (at least partly) causing the responses. According to the behavioral interpretation, each participant would have had experiences that generated intertemporal choice behavioral patterns that could be described (in principle) as a function of amounts and delays of alternative rewards and a rate of temporal discounting. When faced with the procedures used in these studies, the participants' choices were a generalization from their behavioral allocation patterns outside the laboratory and could be (at least partly) described by a discounting parameter.

The cognitive interpretation thus views choices in the laboratory as being caused by the same internal mechanism that also causes choices outside the laboratory, whereas the behavioral interpretation views the choices in the laboratory as being part of a pattern of behavior that extends to behavioral allocation outside the laboratory and that is controlled by contingencies in the historical and current natural environment. Regarding the discounting-drinking relation, the cognitive interpretation would see the discount rate as an important determinant of an individual's decision to drink a certain amount of alcohol on a particular occasion, while the behavioral interpretation would see the discount rate as an important variable in describing how patterns of alcohol consumption develop and change over time in the context of development and change over time in behavioral patterns with respect to nondrinking rewards. The former view is 
concerned with how the discount rate may be an efficient cause of an individual's particular drinking decisions, while the latter view is concerned with how the discount rate can describe drinking within the abstract final causes of the individual's molar behavior patterns. Both of these interpretations are legitimate, and pursuit of their respective empirical implications will lead in different but complementary directions (Rachlin, 1992, 1994). 


\section{References}

Abrams, D. B., \& Niaura, R. S. (1987). Social learning theory. In H. T. Blane \& K. E. Leonard (Eds.), Psychological theories of drinking and alcoholism (pp. 131-178). New York: Guilford

Ainslie, G. (1975). Specious reward: A behavioral theory of impulsiveness and impulse control. Psychological Bulletin, 82, 463-496.

Ainslie, G. (1992). Picoeconomics: The strategic interaction of successive motivational states within the person. Cambridge, England: Cambridge University Press.

American Psychiatric Association (1994). Diagnostic and statistical manual of mental disorders (4 ${ }^{\text {th }}$ Ed.). Washington, DC: American Psychiatric Association.

Becker, G. S., \& Mulligan, C. B. (in press). On the endogenous determination of time preference. Quarterly Joumal of Economics

Becker, G. S., \& Murphy, K. M. (1988). A theory of rational addiction. Journal of Political Economy, 96, 675-700

Bickel, W. K., DeGrandpre, R. J., \& Higgins, S. T. (1993). Behavioral economics: A novel experimental approach to the study of drug dependence. Drug and Alcohol Dependence, 33 , 173192.

Brown, M. B., \& Forsythe, A. B. (1974a). The small sample behavior of some statistics which test the equality of several means. Technometrics, $16,129-132$.

Brown, M. B., \& Forsythe, A. B. (1974b). Robust tests for the equality of variances. Journal of the American Statistical Association, 69, 364-367.

Chutuape, M. A. D., Mitchell, S. H., \& de Wit, H. (1994). Ethanol preloads increase ethanol preference under concurrent random-ratio schedules in social drinkers. Experimental and Clinical 
Psychopharmacology, $2,310-318$.

DeGrandpre, R. J., \& Bickel, W. K. (1996). Drug dependence as consumer demand. In L. Green \& J. H. Kagel (Eds.), Advances in behavioral economics. Vol. 3: Substance use and abuse (pp. 1-36). Norwood, NJ: Ablex.

Gallant, R.A. (1987). Nonlinear statistical models. New York: Wiley.

Gorenstein, E. E., \& Newman, J. P. (1980). Disinhibitory psychopathology: A new perspective and a model for research. Psychological Review, 87, 301-315.

Green, L., Fry, A. F., \& Myerson, J. (1994). Discounting of delayed rewards: A life-span comparison. Psychological Science, $\underline{5}, 33-36$.

Green, L., \& Kagel, J. H. (Eds.) (1996). Advances in behavioral economics. Vol. 3: Substance use and abuse. Norwood, NJ: Ablex.

Green, L., Myerson, J., Lichtman, D., Rosen, R., \& Fry, A. (1996). Temporal discounting in choice between delayed rewards: The role of age and income. Psychology and Aging, 11, 79-84.

Herrnstein, R. J., \& Prelec, D. (1992). A theory of addiction. In G. Loewenstein \& J. Elster (Eds.), Choice over time (pp. 331-360). New York: Russell Sage Foundation.

Hurlbut, T. F., \& Sher, K. (1992). Assessing alcohol problems in college students. Journal of Studies on Alcohol, 41 , 49-58.

Kagel, J. H., Battalio, R. C., \& Green, L. (1995). Economic choice theory: An experimental analysis of animal behavior. Cambridge, England: Cambridge University Press.

Kahneman, D., \& Tversky, A. (1984). Choices, values, and frames. American Psychologist, $\underline{39}, 341-350$.

Khavari, K. A., \& Farber, P. D. (1978). A profile instrument for the quantification and assessment of alcohol consumption: The Khavari Alcohol Test. Journal of Studies on Alcohol, 
$\underline{39}, 1525-1539$.

Kirk, R.E. (1968). Experimental design: Procedures for the behavioral sciences. Belmont, CA: Brooks/Cole.

Loewenstein, G. (1996). Out of control: Visceral influences on behavior. Organizational Behavior and Human Decision Processes, 65 , 272-292.

Loewenstein, G. \& Elster, J. (Eds.) (1992). Choice over time. New York: Russell Sage Foundation.

Logue, A. W. (1988). Research on self-control: An integrating framework. Behavioral and Brain Sciences, $11,665-709$.

Madden, G. J., Petry, N. M., Badger, G. J., \& Bickel, W. K. (1997). Impulsive and selfcontrol choices in opioid-dependent patients and non-drug-using control participants: Drug and monetary rewards. Experimental and Clinical Psychopharmacology, 5, 256-263.

Mazur, J. E. (1987). An adjusting procedure for studying delayed reinforcement. In M. L. Commons, J. E. Mazur, J. A. Nevin, \& H. Rachlin (Eds.), Quantitative analyses of behavior: Vol. 5. The effect of delay and of intervening events on reinforcement value (pp. 55-73). Hillsdale, NJ: Erlbaum.

Moos, R. H., Finney, J. W., \& Cronkite, R. C. (1990). Alcoholism treatment: Context process, and outcome. New York: Oxford University Press.

Myerson, J., \& Green, L. (1995). Discounting of delayed rewards: Models of individual choice. Journal of the Experimental Analysis of Behavior, 64, 263-276.

Poulos, C. X., Le, A. D., \& Parker, J. L. (1995). Impulsivity predicts individual susceptibility to high levels of alcohol self-administration. Behavioural Pharmacology, $\underline{6}, 810-814$.

Rachlin, H. (1974). Self-control. Behaviorism, 2, 94-107. 
Rachlin, H. (1992). Teleological behaviorism. American Psychologist, 47, 1371-1382.

Rachlin, H. (1994). Behavior and mind: The roots of modern psychology. New York: Oxford University Press.

Rachlin, H. (May, 1997). A teleological theory of addiction. Presented at the meeting of the Association for Behavioral Analysis, Chicago, IL

Rachlin, H., \& Green, L. (1972). Commitment, choice, and self-control. Journal of the Experimental Analysis of Behavior, 17, 15-22.

Rachlin, H., Logue, A. W., Gibbon, J., \& Frankel, M. (1986). Cognition and behavior in studies of choice. Psychological Review, 23, 33-45.

Rachlin, H., Raineri, A., \& Cross, D. (1991). Subjective probability and delay. Joumal of the Experimental Analysis of Behavior, 55, 233-244.

Raineri, A., \& Rachlin, H. (1993). The effect of temporal constaints on the value of money and other commodities. Journal of Behavioral Decision Making, 6, 77-94.

Room, R. (1989). The U.S. general population's experiences of responding to alcohol problems. British Journal of Addiction, 84, 1291-1304.

Sarfati, P., \& White, K. G. (1991). Impulsivity in social drinkers. New Zealand Journal of Psychology, 20, $41-48$.

Selzer, M. L. (1971). The Michigan Alcoholism Screening Test: The quest for a new diagnostic instrument. American Journal of Psychiatry, 127, 1653-1658.

Sher, K. J., \& Trull, T. J. (1994). Personality and disinhibitory psychopathology: Alcoholism and antisocial personality disorder. Journal of Abnormal Psychology, 103, 92-102.

Silberberg, A., Murray, P., Christensen, J., \& Asano, T. (1988). Choice in the repeatedgambles experiment. Joumal of the Experimental Analysis of Behavior, 50, 187-195. 
Sobell, L. C., Cunningham, J. A., \& Sobell, M. B. (1996). Recovery from alcohol problems with and without treatment: Prevalence in two population surveys. American Journal of Public Health, $\underline{86}, 966-972$.

Tucker, J. A., Vuchinich, R. E., \& Gladsjo, J. A. (1994). Environmental events surrounding natural recovery from alcohol-related problems. Journal of Studies on Alcohol, $\underline{5}$, 401-411.

Tucker, J. A., Vuchinich, R. E., \& Pukish, M. A. (1995). Molar environmental contexts surrounding recovery from alcohol problems in treated and untreated problem drinkers.

Experimental and Clinical Psychopharmacology, 3, 195-204.

Vuchinich, R. E. (1995). Alcohol abuse as molar choice: An update of a 1982 proposal. Psychology of Addictive Behaviors, 9 , 223-235.

Vuchinich, R. E. (1997). Behavioral economics of drug consumption. In B. A. Johnson \& J. D. Roache (Eds.), Drug addiction and its treatment: Nexus of neuroscience and behavior (pp. 73 90). Philadelphia: Lippincott-Raven

Vuchinich, R. E., \& Calamas, M. L. (1997). Does the repeated gambles procedure measure impulsivity in social drinkers? Experimental and Clinical Psychopharmacology, 5, 157-162.

Vuchinich, R. E., \& Simpson, C. A. (submitted for review). Hyperbolic temporal discounting in social drinkers and problem drinkers

Vuchinich, R. E., \& Tucker, J. A. (1983). Behavioral theories of choice as a framework for studying drinking behavior. Journal of Abnormal Psychology, 92, 408-416.

Vuchinich, R. E., \& Tucker, J. A. (1988). Contributions from behavioral theories of choice to an analysis of alcohol abuse. Journal of Abnormal Psychology, 97, 181-195.

Vuchinich, R. E., \& Tucker, J. A. (1996). Alcoholic relapse, life events, and behavioral theories of choice: A prospective analysis. Experimental and Clinical Psychopharmacology, 4, 19 - 
28.

Vuchinich, R. E., Tucker, J. A., \& Harllee, L. M. (1988). Behavioral assessment (of alcohol dependence. In D. M. Donovan \& G. A. Marlatt (Eds.), Assessment of addictive behaviors (pp. 51-93). New York: Guilford Publications

Vuchinich, R. E., Tucker, J. A., \& Rudd, E. J. (1987). Preference for alcohol consumption as a function of amount and delay of alternative reward. Journal of Abnormal Psychology, 96, 259263.

Wechsler, H., Dowdall, G. W., Davenport, A., \& Castillo, S. (1995). Correlates of college student binge drinking. American Journal of Public Health, $\underline{85}, 921-926$.

White, J. L., Moffit, T. E., Caspi, A., Bartusch, D. J., Needles, D. J., \& Stouthamer-Loeber, M. (1994). Measuring impulsivity and examining its relationship to delinquency. Journal of Abnormal Psychology, 103, 192-205. 


\section{Author Note}

The laboratory studies discussed in this chapter have been reported in Vuchinich and Simpson (submitted). The study with problem drinkers in the natural environment was supported by grant \#AA08972 from the National Institute on Alcohol Abuse and Alcoholism (Jalie A. Tucker, Principal Investigator, and Rudy E. Vuchinich, Co-Principal Investigator). 
Figure Captions

Figure 1. Figure illustrates dynamics in intertemporal choice with relatively higher and lower rates of hyperbolic and exponential discounting of delayed rewards. The rewards are represented as vertical bars, with amount indicated by their height and time of availability indicated by their location on the abscissa. In each panel, a smaller sooner reward (e.g., alcohol consumption) is available at time 6 and a larger later reward (e.g., valuable nondrinking activity) is available at time 10. The curves to the left of the rewards are delay discount functions that represent reward value during the times before they are available; the reward with the highest value curve at the time of choice will be preferred. The two left and two right panels show hyperbolic and exponential discount functions, respectively, and the two top and two bottom panels show relatively higher and lower rates of discounting, respectively. The hyperbolic and exponential discount functions were generated from Equation 1 and Equation 2, respectively.

Figure 2. Figure shows data from two individual participants that were generated by the hypothetical money choice task. The top and bottom panels illustrate relatively low and high rates of temporal discounting, respectively. Each data point represents the amount of immediately available (hypothetical) money that is subjectively equivalent in value to a larger amount of (hypothetical) money that is available after a series of delays. The filled and unfilled circles are from the $\$ 1,000$ and $\$ 10,000$ conditions, respectively. Present value is scaled as the percentage of the larger delayed money amount.

Figure 3. Figure shows hyperbolic discount functions for the $50^{\text {th }}$ percentile averaged $\mathrm{k}$ values for the heavy drinkers (solid line) and light drinkers (broken line) in Study 1. The functions were generated from Equation 1.

Figure 4. Figure shows hyperbolic discount functions for the $50^{\text {th }}$ percentile $\underline{k}$ values for the 
problem drinkers (solid line) and light drinkers (broken line) in Study 2. The functions were generated from Equation 1. 
Hyperbolic Discounting

Exponential Discounting

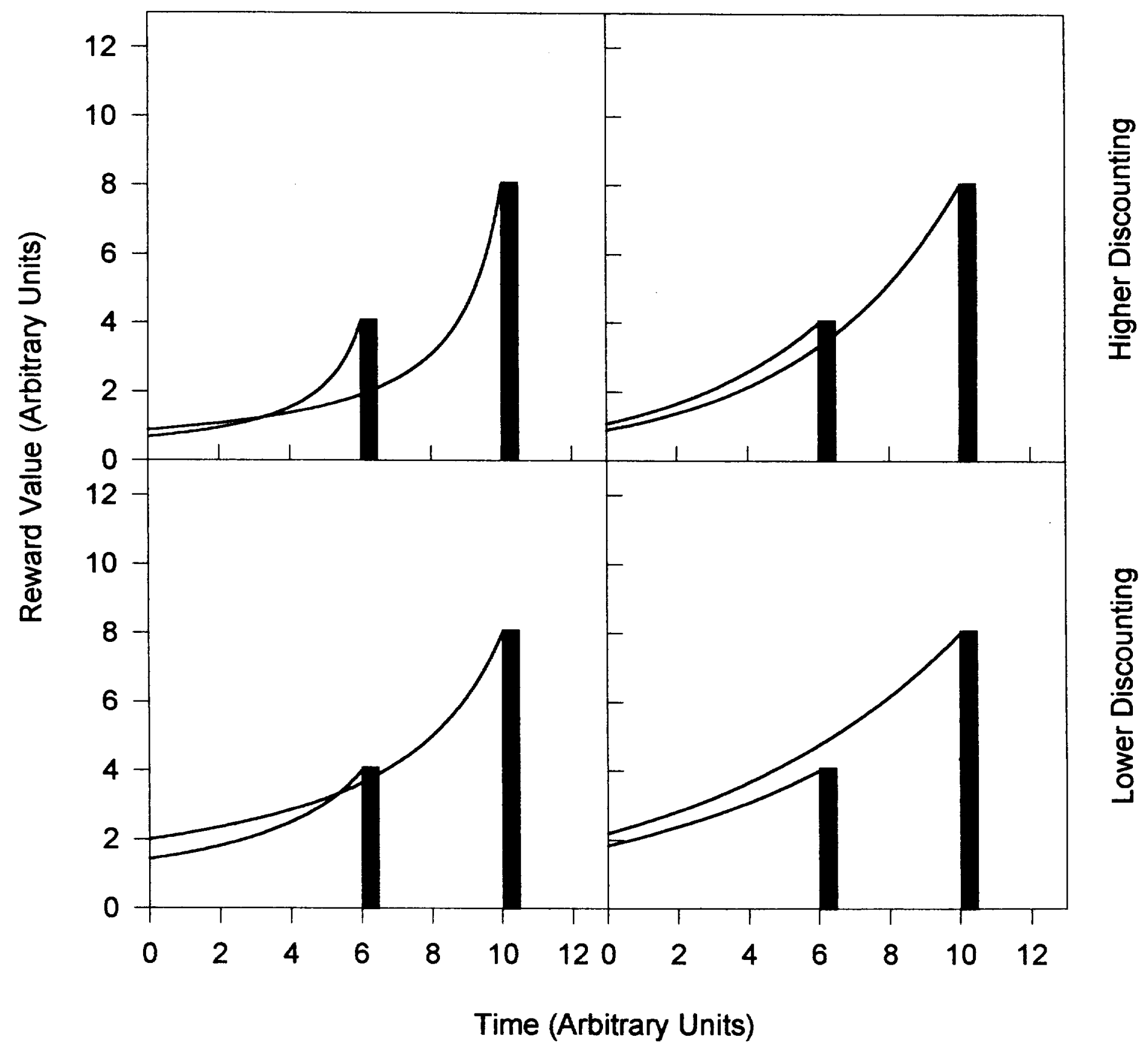




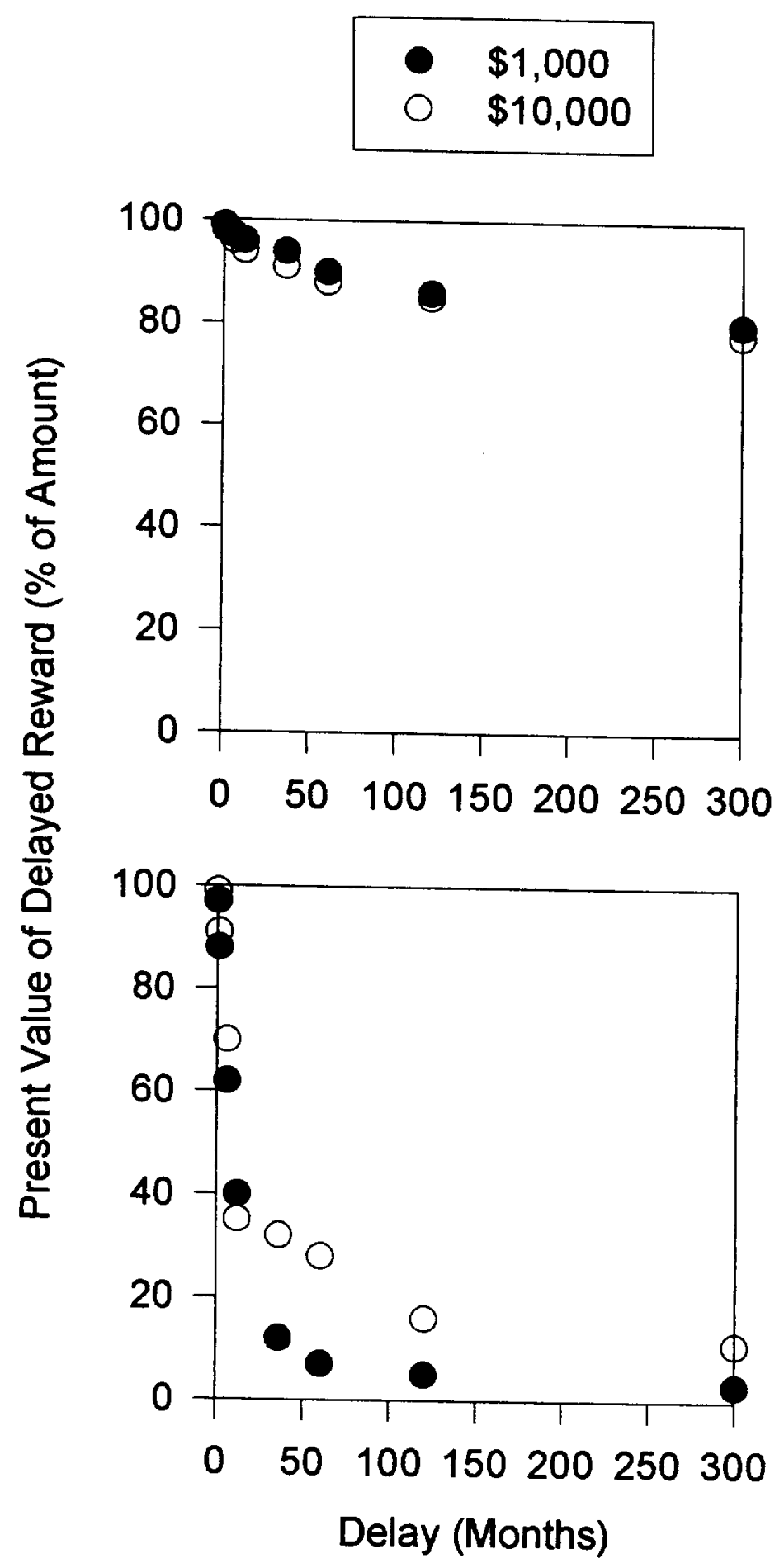




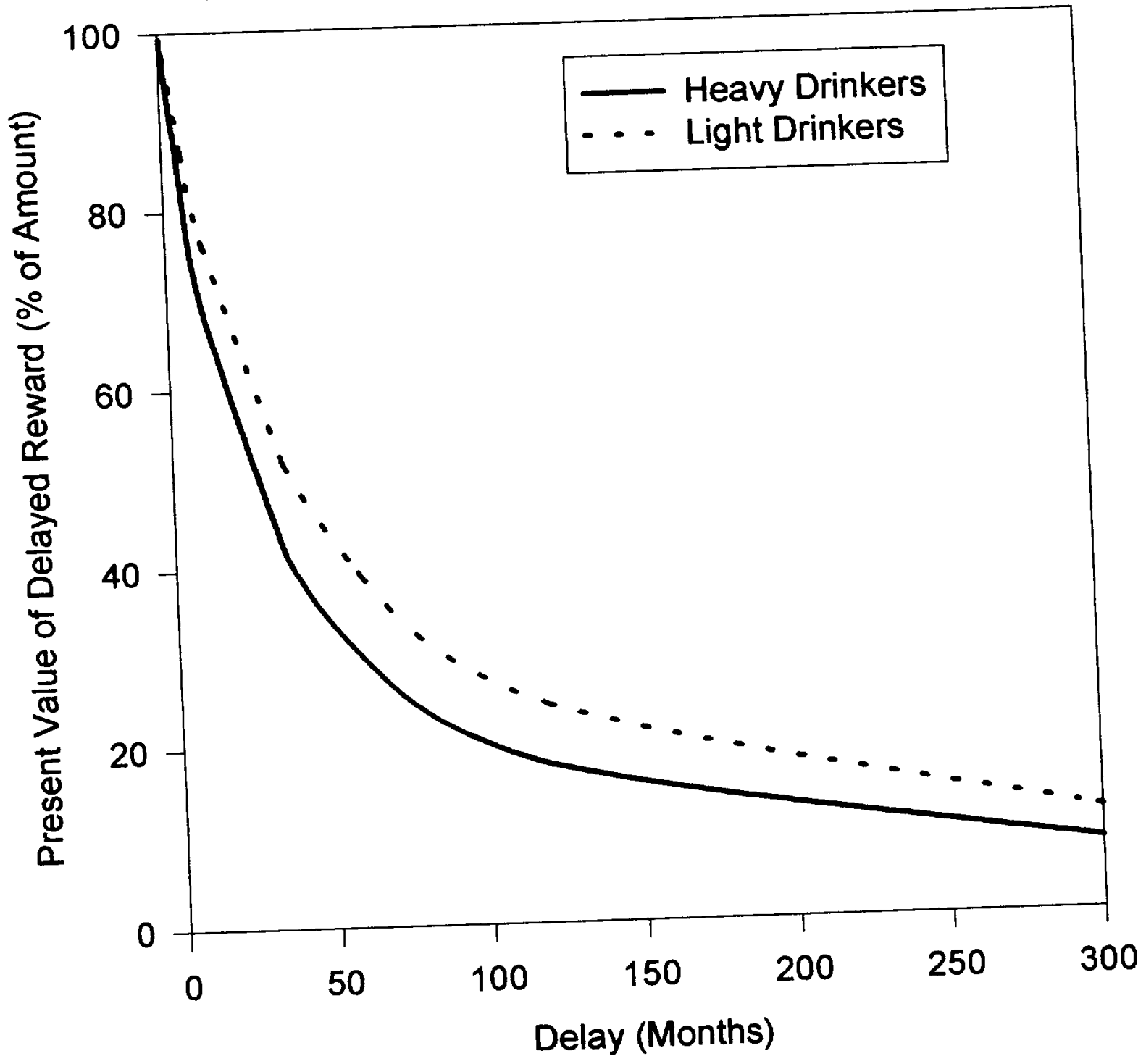




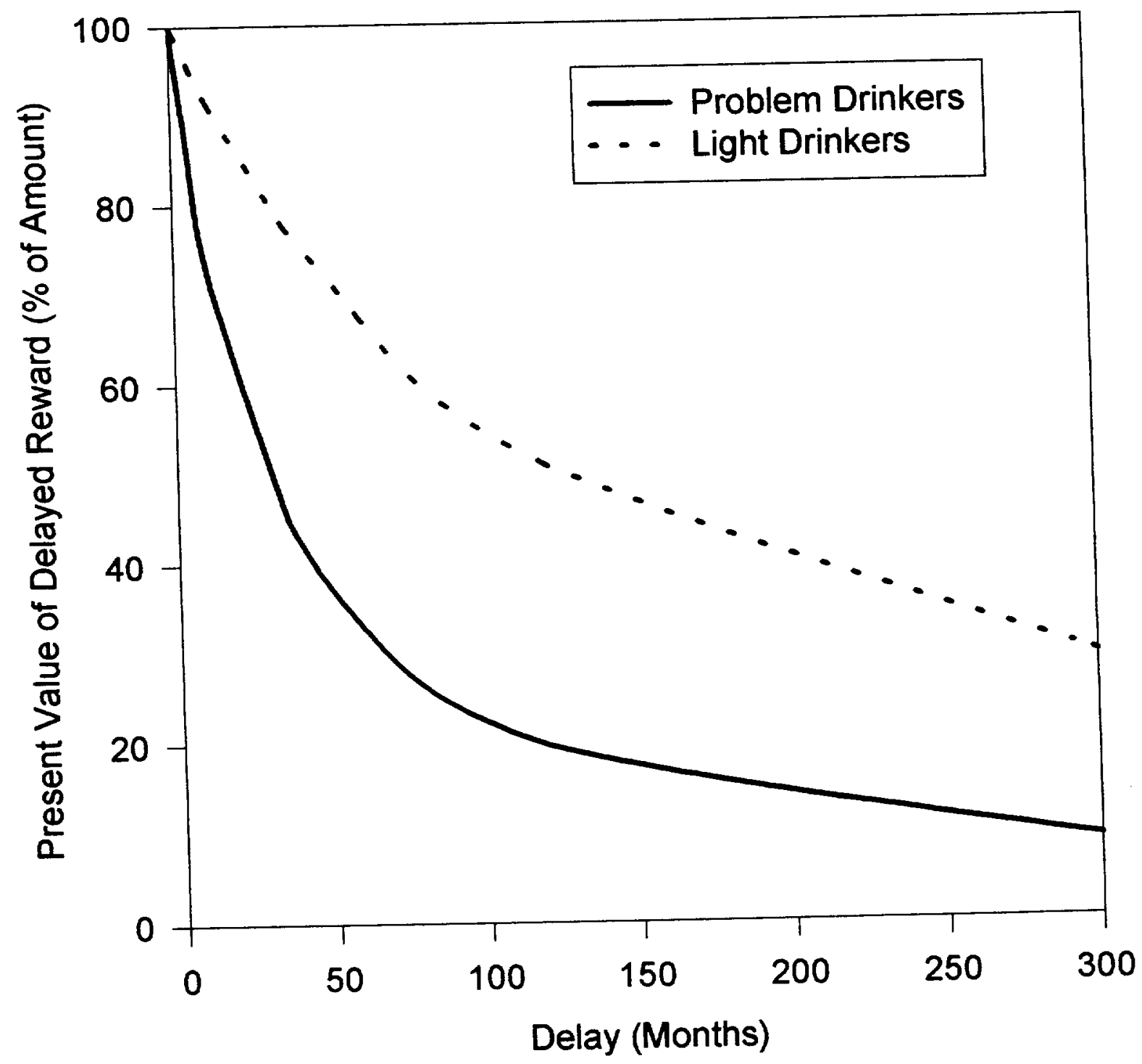

